\title{
RICARDO CARVALHO CALERO NA RESISTENCIA DOS TEMPOS DA GUERRA E DA POSCUERRA (1936-1980)
}

\author{
RICARDO CARVALHO CALERO IN THE RESISTANCE MOVEMENT \\ DURING THE SPANISH CIVIL WAR AND POST-CIVIL WAR PERIOD (1936-1980)

\section{Carmen Blanco \\ Universidade de Santiago de Compostela}

\begin{abstract}
Resumo: Este traballo achégase aos distintos tempos da traxectoria vital, profesional e intelectual de Ricardo Carvalho Calero nas catro décadas e media que van da segunda metade da dos trinta, marcada polo levantamento de 1936, á década dos setenta final da ditadura, marcada pola morte de Franco en 1975. A achega traza unha visión xeral do autor que constata a coherencia dunha personalidade que se adapta ás diversas circunstancias de guerra, ditadura e transición á democracia. Evidencia a resistencia antifascista fronte á represión na defensa da República coas armas e a supervivencia no cárcere e no exilio interior coas letras.
\end{abstract}

\begin{abstract}
This work examines different times in the life and professional and intellectual trajectory of Ricardo Carvalho Calero over the four and a half decades ranging from the late 1930s (marked by the uprising of 1936) to the 1970s and the end the Franco dictatorship (marked by the death of the dictator in 1975). It provides an overview of the author, confirming the coherence of a personality that adapts to the various circumstances of war, dictatorship and the transition to democracy. It analyses antifascist resistance against repression in the defence of the Republic through arms and survival in prison and inner exile through writing.
\end{abstract}

Palabras chave: Galicia, memoria, filoloxía, lingua, literatura, Ricardo Carvalho Calero.

Key words: Galicia, memory, philology, language, literature, Ricardo Carvalho Calero. 


\section{VISIÓN XERAL DO CARVALHO CALERO UN E DOS CARVALHO CALERO MOITOS}

O presente escrito achegarase aos distintos momentos da traxectoria vital, profesional e intelectual de Ricardo Carvalho Calero durante as catro décadas e media que van da segunda metade dos anos trinta, marcada polo levantamento militar do dezaoito de xullo de 1936, á década dos setenta final da ditadura, marcada pola morte de Franco en 1975. A achega trazará unha visión xeral do RCC un e dos RCC moitos para constatar o mantemento da coherencia de RCC e os cambios derivados das adaptacións ás diversas circunstancias dos distintos tempos nesta época convulsa de guerra, ditadura e transición cara á democracia, de destrutivos enfrontamentos bélicos fratricidas e feroces discordias políticas. Tal achega destacará a resistencia de RCC que, fronte ás situacións represivas, aguantou na defensa da República coas armas e na supervivencia da derrota do réxime democrático no cárcere e no exilio interior coas letras.

Esta visión xeral é a que tratei de transmitir nos libros e nos artigos cos que din a coñecer a Carvalho Calero, unha visión aberta á diversidade dos datos máis obxectivos e sen prexuízos, que agora sintetizo con matices aprendidos na re-lectura e análise da obra caleriana e dos estudos sobre ela.

\section{CONTEXTO XERAL: RCC MEMBRO DO SEMINARIO DE ESTUDOS GALEGOS NO TRÁNSITO DO MODERNISMO AO POSMODERNISMO INTERNACIONAL}

Ricardo Carvalho Calero (Ferrol, 1910 - Santiago de Compostela, 1990) é un sabio polímata, polígrafo, políglota, activista político-cultural, educador, profesor e, por riba de todo, escritor culto do século XX.

A súa vida e a súa obra sitúanse no tránsito do modernismo ao posmodernismo internacionais, no contexto xeral do pensamento, as artes e as humanidades, e no tempo do 36, no contexto histórico, bélico e posbélico, marcado polas dúas guerras mundiais e a guerra civil ou de España. Estas coordenadas galegas, españolas, europeas e universais circunscriben unha vida e unha obra cun antes e un despois do levantamento militar fascista de 1936.

Ao mesmo tempo, a vida e a obra do ferrolán sitúao como ser da segunda promoción do Seminario de Estudos Galegos (1923), tempo no que se autodefiniu coas tres dimensións integradas deste organismo científico: ciencia, creación e política. Neste sentido a figura de Carvalho Calero enmárcase dentro do proceso galeguista e do concreto movemento social galeguista, anunciado no pregaleguismo do XVIII, iniciado no XIX e culminado no XX, como discípulo da 
mestría da ilustración e do rexurdimento e dos seus mestres das Irmandades da Fala (1916) e de Nós (1920).

\section{CARACTERÍSTICAS XERAIS: RCC HUMANISTA EXISTENCIAL, PROGRESISTA, GALEGUISTA E INDEPENDENTE}

A personalidade complexa de Carvalho Calero manifesta diversas facetas. É un creador e pensador humanista existencial, de ideas políticas progresistas e socialdemócratas, con principios liberais baseados no libre criterio individual, de sentimento relixioso cristián, galeguista e independente. Estas características, na súa dimensión especificamente política, concretáronse particularmente na militancia na Federación Universitaria Escolar (1926) e no Partido Galeguista (1931), exercitada con brillantez antes do levantamento do 36, e na afiliación como traballador á Unión General de Trabajadores, que o levou a combater na defensa de Madrid, como miliciano no Batallón Félix Barzana da Federación de los Trabajadores de la Enseñanza de la UGT, e na fronte de Andalucía, no estado maior como tenente do exército republicano.

Todas estas características ficaron unificadas no compromiso social galeguista de xuventude que deu sentido aos quefaceres do conxunto da súa vida.

\section{TRAXECTORIA VITAL XERAL: RCC DO PRETÉRITO IMPERFECTO Á POESÍA PERDIDA E DO FUTURO CONDICIONAL ÁS RETICÊNCIAS...}

Na traxectoria vital de Carvalho Calero perfílanse dúas grandes etapas derivadas da traxedia da guerra (1936-1939) e do cárcere como consecuencia da derrota republicana (1939-1941). Esta traxedia causou a crise da súa brillante vocación política de xuventude e o recoñecemento definitivo da vocación creadora e da devoción investigadora.

Podemos dar nome metafórico a esas dúas grandes etapas coas denominacións dos títulos das súas compilacións poéticas, cargados de intelixente ironía: do Pretérito imperfecto á Poesía perdida e do Futuro condicional ás Reticências...

Do Pretérito imperfecto á Poesía perdida nomearía a primeira grande etapa, que vai de 1910 a 1941 e transcorre en Galicia (Ferrol, 1910-1926 e 1933-1936, e Santiago de Compostela, 1926-1933,) e fóra de Galicia (Madrid, Valencia e Andalucía, 1936-1941). Esta denominación parte dos títulos da recompilación da poesía galega Pretérito imperfecto (1927-1961) (1980), preparada e publicada polo autor en vida o ano da súa xubilación, e da recompilación da poesía española Poesía perdida (1993), non publicada por compromiso monolingüe galego, mais gardada 
polo escritor e editada e titulada no seu conxunto por Claudio Rodríguez Fer como obra póstuma que o autor deixara perfectamente preparada. Do Futuro condicional ás Reticências... nomearía a segunda grande etapa, que vai de 1941 a 1990 e transcorre toda en Galicia (Ferrol, 1941-1950; Lugo, 1950-1965, e Santiago de Compostela, 1965-1990). Esta denominación parte dos títulos das recompilacións da última etapa antes da xubilación, Futuro condicional (1961-1980) (1982), e da derradeira etapa da vida, Reticências... (1986-1989) (1990), que aparecería postumamente no ano da morte.

Son dúas grandes etapas sinaladas polo propio Carvalho Calero, sen límites estritos na escrita, e dentro do Carvalho Calero un que tamén el precisou.

\section{OBRA DE SETENTA ANOS:}

RCC CREADOR E INVESTIGADOR

Nesta traxectoria vital Carvalho Calero realiza unha grande obra de creación e investigación, en cantidade e calidade, no tránsito duns setenta anos.

Durante sete décadas a creación foi cronoloxicamente a primeira en aparecer e a que se mantivo constante e permaneceu ata a fin, aínda que non sempre se dese a coñecer. $\mathrm{O}$ autor tense autodefinido como creador e particularmente como creador de inspiración lírica que envolve todo o seu conxunto creativo.

Dita creación maniféstase en catro dimensións básicas: a escrita, a dirección teatral, a oratoria e a tradución. A dimensión escrita en prosa e verso galegos é sen dúbida a central, a máis coñecida e a máis recoñecida. Esta escrita defíneo como poeta, por vocación e dedicación, mais abrangue os tres grandes xéneros literarios propiamente ditos: o lírico, o épico e o dramático. A lírica en verso está escolmada nas citadas compilacións de poesía dos últimos anos ademais de nas Cantigas de amigo e outros poemas (1980-1985) (1986); a prosa narrativa en Narrativa completa (1984), coas importantes achegas na narrativa longa de A xente da Barreira (1951), primeira obra galega deste tipo editada en Galicia na posguerra, e de Scórpio (1987), creación testamentaria polifónica de autoficción, e o teatro en Teatro completo (1982), co legado último "Os xefes" (1980). É extraordinaria a contribución á prosa no xénero didáctico e no xornalístico, con numerosos libros que van dos primeiros Sete poetas galegos (1955) ao legado derradeiro Umha voz na Galiza (1992), e entre os que hai obras fundamentais e emblemáticas: Historia da literatura galega contemporánea (1975), Estudos rosalianos (1979), os dous volumes Libros e autores galegos. Dos trovadores a Valle-Inclán (1979) e Libros e autores galegos. Século XX (1982), Problemas da língua galega (1981), Letras galegas (1984) ou Escritos sobre Castelao (1989). A oratoria ten en certos casos tamén forma escrita e atópase en boa medida dispersa. E a tradución e adaptación coñecida é menos numerosa. 
Neste conxunto destacan as diferenzas existentes entre escrita e publicación que sinalan a presenza dunha escrita íntima, nacida da catarse, que non coincide cronoloxicamente sempre coa súa publicación e que mesmo permanece inédita durante tempo por diversos motivos. A publicación está motivada por distintas necesidades persoais ou sociais e as distancias entre escrita e publicación dificultan a caracterización das sucesivas etapas do escritor e indican, asemade, a reescritura da obra anterior á luz dos avances dos distintos tempos e a coherencia da personalidade de Carvalho Calero.

Esta obra está escrita en dúas linguas básicas: o español e o galego. A primeira foi a do comezo como escritor e a segunda foi a da elección logo na creación por compromiso galeguista. As dúas conteñen cantidade e calidade, mais o esforzo extensivo e intensivo do autor concéntrase na obra en lingua galega.

O conxunto xeral predominante é esteticamente ecléctico e está caracterizado quizá pola comedida vangarda simbiótica con elementos clásicos. O contido dese conxunto é o humanismo existencial proxectado nas tres direccións sinaladas simbolicamente polo poeta na compilación de Futuro condicional: a dirección transcendente de Excalibur, a dirección erótica de Venusberg e a dirección social de Avalón.

A obra de investigación, fóra uns comezos na filosofía do dereito centrados na cultura grega clásica e na historia política, é especialmente filolóxica e abrangue dúas grandes dimensións, a lingüística e a literaria, en harmonía co nome da Cátedra de Lingüística e Literatura Galega da Universidade de Santiago de Compostela, obtida en 1972. Na lingüística céntrase na iberorrománica, na galegoportuguesa e especificamente na lingua galega, onde desenvolve dúas grandes liñas básicas, a gramática e a glotopolítica (sociolingüística, política lingüística...) cunha importancia histórica galeguizadora culta de recuperación da irmandade galego lusa. Na literatura galega desprégase tamén nas dúas grandes liñas da historia e da crítica, tratadas no contexto da literatura xeral e comparada e con coñecemento da teoría literaria. Metodoloxicamente o seu criterio teórico básico é o sincretismo ecléctico proxectado sobre os textos segundo as características dos mesmos. Esta obra filolóxica é fundacional.

\section{OBRA DE CATRO DÉCADAS E MEDIA: RCC RESISTENTE NA GUERRA E NA POSGUERRA}

\section{RESISTENCIA MADURA LIGADA AO BRILLO NOVO E Á PROXECCIÓN DA VELLEZ}

Dentro das anteditas traxectorias xerais, os tempos que van do levantamento militar de 1936 á xubilación suman case catro décadas e media da madurez da vida de Ricardo Carvalho Calero e constitúen unha larga etapa central resistente: a 
do Carballo da guerra e da posguerra, que segue ao Carballo republicano e nacionalista de esquerdas de preguerra e antecede ao Carvalho da sabedoría final do activismo cultural democrático e reintegracionista.

Son tres Carvalhos de tres idades da vida humana distintas - xuventude, madurez e ancianidade-, coincidentes con tres tempos históricos distintos e diferentes nas súas realizacións adecuadas ás circunstancias antitéticas das diversas ditaduras e das variacións da democracia republicana de preguerra e da democracia con autonomía de posguerra fronte á dura ditadura de Franco. Desde os principios comúns do Carvalho un, estes grandes Carvalhos proxectan na carballeira da historia o brillo da loita xuvenil, da resistencia madura e da proxección na idade do máximo saber.

\section{TRANSCENDENCIA DA RESISTENCIA ANTIFASCISTA COAS ARMAS E COAS LETRAS}

Desta maneira, o prolongado período do segundo Carballo comparte raíces cos outros dous e nútrese do mesmo proxecto persoal, pensado e practicado desde o primeiro Carballo ata o derradeiro, ao tempo que acada unha transcendencia enorme na resistencia antifascista, progresista e galeguista do combate a favor da República, durante a guerra de 1936-1939, da supervivencia no cárcere de Xaén, de 1939 a 1941, e no exilio interior, con liberdade vixiada e prohibición do exercicio de funcións públicas, ata a reintegración nesas funcións, na metade da década dos sesenta.

Nestes tempos tan convulsos de guerra, ditadura e transición cara á democracia, marcados polos enfrontamentos bélicos e as discordias políticas, a persoa do profesor e educador, do creador e do investigador sobreviviu loitando a favor da vida cos particulares principios liberais, cristiáns, socialdemócratas e humanistas sinalados.

Son tempos de resistencia fronte á morte e ao totalitarismo, na supervivencia da guerra e na resistencia do exilio interior da posguerra e da transición, nos que conduciu afirmativamente a súa profunda e precoz vocación literaria e a súa ansiada devoción profesoral e universitaria, cun traballo incansable no exército republicano, no cárcere, no profesorado privado e público e na universidade, co estudo, a docencia, a investigación e a creación.

Nesta difícil resistencia fronte aos poderes dominantes tratou de manter, con determinación intelixente e sensible, a coherencia dos principios básicos do seu compromiso de cando novo. Este resistente amor a Galicia, que deu sentido ao quefacer de toda a súa vida, foi posible, nos tempos de "guerras" e "ditaduras" de dentro e de fóra, grazas ao apoio firme da muller, a profesora de historia María Ignacia Ramos (1910-2001), escritora ocasional co pseudónimo María Silgar, e á axuda de compañeiros nos ideais antifascistas, familiares e amigos. Tal amor 
pola súa Galicia ideal tivo por guía o saber experimentado e maduro do Carballo Calero destes anos.

OS TEMPOS DISTINTOS DA GUERRA, DO CÁRCERE, DA DITADURA E DA TRANSICIÓN: RCC de Madrid a Valencia e Andalucía e de Ferrol a Lugo (1936-1941 E 1941-1950), RCC de Lugo a Compostela (1950-1965) e RCC en Santiago de Compostela (1965-1980)

Para o home, separado fisicamente da muller e sen coñecer a filla primoxénita, Margarita, que nace á par do levantamento de 1936, cando el está en Madrid para realizar oposicións ao profesorado de ensino medio na materia de lingua e literatura española, combatente na guerra, preso en Andalucía, xulgado en consello de guerra e condenado a doce anos e un día de reclusión maior, dos que cumpre dous por redución, estes anos foron unha paréntese persoal despois da que retoma a vida coa familia en Ferrol, a comezo dos anos corenta, e nace a segunda filla, María Victoria.

Logo desa paréntese de finais dos anos trinta e comezo dos corenta, as décadas seguintes serán de progresivo renacemento e consolidación, en consonancia cos cambios dos tempos históricos: a década dos corenta, de continuación da supervivencia na escrita íntima e o silencio relativo en Ferrol; a dos cincuenta e primeira metade da dos sesenta, de recuperación privada e pública en Lugo; a da segunda metade da dos sesenta e a dos setenta, a do avance normalizador en Santiago de Compostela e a aceleración galeguista despois da morte do ditador, de cara á manifestación na maior liberdade da etapa derradeira.

En torno á época da guerra e prisión fóra de Galicia, na que mantén contactos socialistas e galeguistas, resiste escribindo en galego, mais tamén en español na ditadura. Desta época son as obras poéticas "Avena loca", "Romancero de apócrifos e canónicos" e "Teoría de Eva", que, xunto coas revisións dos libros de preguerra Trinitarias (1928) e La soledad confusa (1932), "Versos para olvidar" e "Versos para romper", integran a citada Poesía perdida (1993).

Os seguintes anos da década dos corenta son de traballo intenso no ensino privado en Ferrol para gañar a vida na liberdade provisoria, vixiada e acosada. Fronte á represión ditatorial, a terapia activa do traballo e da escrita é unha receita salvadora aplicada ante as adversidades, segundo expón a propósito de "O lar de Clara" no "Limiar" á citada Narrativa completa: "son páginas escritas para loitar contra a destrutora hostilidade dun tempo valeiro e adverso que había que encher e conjurar coa actividade que nos defende de nós mesmos e do mundo circunstante".

Esta resistencia activa centrada na escrita parece tela seguido sempre na vida e moi especialmente no período da reclusión e da ditadura férrea nos tempos de Ferrol, mais tamén durante a guerra, toda a ditadura e a transición. E así parte 
da obra de creación que publica nas etapas posteriores a esta de forte censura dos corenta foi escrita, ideada ou revisada nestes tempos ou noutros inmediatamente posteriores e transcrita, re-escrita e recreada con proximidade á publicación.

Desta época é a obra de temática galaico-andaluza inspirada no cantar "O trebo das catro follas". Está datada en 1944 e conservada inédita ata que eu a exhumei en 1997, confirmando estes feitos a caracterización esencial do escritor como poeta culto.

En 1950 a solidariedade da resistencia agrupada en torno á Editorial Galaxia e o apoio do mecenas Antonio Fernández López ofrécenlle en Lugo a dirección de facto do Colexio Fingoi, unha creación educativa integral e integrada no medio segundo as directrices do Instituto Escuela e da Institución Libre de Enseñanza na que traballará quince anos.

Estes tempos de Lugo son os da recuperación da cultura galega no interior e neles Carballo Calero terá unha función fundamental. Na creación, a publicación de A xente da Barreira contribúe á renovación da narrativa cun neorrealismo sintético herdeiro do tema de Otero e Castelao sobre os señores da terra. E do mesmo modo, na poesía e no teatro achega humanismo simbólico-existencial, mítico, relixioso e existencialista en Anxo de terra (1950), Poemas pendurados dun cabelo (1952) e Salterio de Fingoy (1961); "A farsa de Orfeo" (1963) ou "A arbre" (1965). Ao mesmo tempo exercerá como director teatral no Colexio Fingoi levando á escena obras da dramaturxia internacional en distintas linguas e o lance de Pimpinela de Os vellos non deben de namorarse de Castelao. Desta época é a adaptación "O redondel" (1951), drama de Li Hsing Tao, incorporada ao Teatro completo de 1982. No ensaio, publica Historia da literatura galega contemporánea (1963), base do estudo científico da literatura galega, e os libros Sete poetas galegos, Aportaciones a la literatura gallega contemporánea (1955), Contribución ao estudo das fontes literarias de Rosalía (1959) e Versos iñorados ou esquencidos de Eduardo Pondal (1961). É este o momento do comezo do traballo institucional oficial do intelectual, co ingreso na Real Academia Galega en 1958.

A apertura do réxime posibilítalle a entrada no ensino público como agregado de lingua e literatura españolas no Instituto Rosalía de Castro en Santiago en 1965 e como encargado das clases de lingua e literatura galegas na Universidade de Santiago de Compostela. Na universidade, na que será primeiro Catedrático de Lingüística e Literatura Galega, intensifica o traballo académico e como membro do Instituto de Estudios Gallegos Padre Sarmiento, da Sociedad Española de Literatura General y Comparada ou da Real Academia Galega e participa na elaboración das Normas ortográficas e morfolóxicas do idioma galego, desenvolvidas e aprobadas durante este período. Incrementa as publicacións sobre lingua e literatura galegas con doce libros, entre eles as achegas máximas da especialidade: 
Gramática elemental del gallego común (1966), base do tema que ampliará ata a sétima edición de 1979, e Historia da literatura galega contemporánea (1975), traducida parcialmente ao castelán en 1976. En torno a eles, como complemento, as antoloxías, edicións e recompilacións que amplían o arco temporal e espacial da especialidade: Breviario antolóxico de la literatura gallega contemporánea (1966), Prosa galega 1, 2 e 3 (1976, 1978, 1980), Teatro Nós de Risco, Otero e Castelao (1979), Sobre lingua e literatura galega (1971), Literaturas hispánicas. Unidad didáctica 1 e 2 (1977) ou os citados Libros e autores galegos. Dos trovadores a Valle-Inclán e Problemas da língua galega. E conformando o sentido deles, como interese maior, Rosalía de Castro, tema do nomeado discurso de ingreso na RAG, Contribución ao estudo das fontes literarias de Rosalía e tema da lección na oposición á cátedra, Particularidades morfológicas del lenguaje de Rosalía de Castro (1972), obxecto das diversas reedicións de Cantares gallegos (1969) e Poesías (1972), do citado Estudos rosalianos e continuo motivo de atención, sempre presente onde el estaba presente ata a fin da súa vida, por considerala clásica por antonomasia da literatura galega no panorama universal. Na creación hai un relativo silencio en libro que fala da vocación teatral a recompilación Catro pezas (1971) e fala do rexeitamento ético e estético das imposturas da moda socialrealista dominante a ausencia de libros doutros xéneros, confirmado coa praxe positiva da publicación en 1980 da emblemática recompilación poética Pretérito imperfecto.

\section{RCC DE GALIZA A GALIZA: O REDONDEL}

O mellor de Ricardo Carvalho Calero revélase na volta a Galiza dada grazas ao amor e á solidariedade durante a difícil resistencia antifascista dos tempos da guerra e posguerra na epifanía da autenticidade como en $O$ redondel. 